\title{
ENTRE A DIVERSIDADE E O ANTAGONISMO Práticas articulatórias da discursividade LGBT no Ministério da Cultura*
}

\section{José de Souza Muniz Jr. (1)}

https://orcid.org/0000-0002-1919-0030

\author{
Alexandre Almeida Barbalho ${ }_{(2)}$ \\ https://orcid.org/0000-0003-4612-6162 \\ (1) Centro Federal de Educação Tecnológica de Minas Gerais (Cefet-MG), Belo Horizonte - MG, Brasil. E-mail: jmunizjr@cefetmg.br \\ (2) Universidade Estadual do Ceará (UECE), Fortaleza - CE, Brasil. E-mail: alexandre.barbalho@uece.br
}

DOI: $10.1590 / 3510209 / 2020$

\section{Política cultural e coletividade LGBT}

Este trabalho apresenta os resultados de uma pesquisa cujo objeto é um conjunto de programas, açóes e mecanismos institucionais do Ministério da Cultura (MinC), que passaram a contemplar a coletividade $\mathrm{LGBT}^{1}$ durante os governos de Luís Inácio Lula da Silva e Dilma Rousseff. O marco inicial desse processo é a criação, em 2004, do Grupo de Trabalho de Promoção da Cidadania GLTB, liga-

* Pesquisa financiada pelo Programa Nacional de Pós-Doutorado (PNPD) da Capes. Artigo apresentado no GT "Pluralismo, identidade e controvérsias sociopolíticas" (41ㅇ Encontro Nacional da ANPOCS, 2017). Agradecemos os professores Joanildo Albuquerque Burity (Fundaj) e Paula Montero (USP) - coordenadores do GT - e demais colegas pelos comentários e sugestôes.

Artigo recebido em: 13/06/2018

Aprovado em: 29/08/2019 do à Secretaria de Identidade e Diversidade Cultural (SID) do Ministério. O objetivo central da pesquisa foi compreender a institucionalização das agendas culturais do movimento LGBT brasileiro via política cultural em âmbito federal, a partir $\mathrm{da}$ análise de documentos do $\mathrm{MinC}$ e de depoimentos públicos de agentes desse universo, a partir da Teoria do Discurso (TD) de Laclau e Mouffe (2010).

Consideramos, como problema central a essa análise, a tensão entre os valores dos representantes desse grupo e aqueles vigentes no espaço público mais amplo e nos espaços de discussão e formulaçấo da política cultural. A hipótese principal do estudo é que tais programas e açóes teriam procurado administrar os potenciais conflitos entre valores minoritários e valores hegemônicos na sociedade brasileira, no que diz respeito às orientaçóes sexuais $e$ às identidades de gênero, bem como à liberdade de exercê-las. Por esse viés, os antagonismos colocados pelas diferenças encampadas pelo movimento 
LGBT teriam sido encobertos e neutralizados pelo discurso liberal da diversidade, que encontrou particular adesão no âmbito da política cultural brasileira a partir dos anos 2000. Tais problemas situam o referido objeto numa discussão mais ampla sobre o lugar da diferença nas sociedades contemporâneas e sobre os processos de invenção sociopolítica das identidades, os quais engendram "novas modalidades de gerenciamento e de partilha do espaço político" (Montero, 2012).

O pano de fundo dessa discussão é a existência de um "campo de discursividade" (Laclau e Mouffe, 2010) que posiciona as minorias como sujeitos de direitos culturais, dignos de atenção diferenciada (Sodré, 2005; Barbalho, 2005). . No âmbito específico das políticas culturais, essas discursividades mobilizam, a partir da noção de "diversidade", a ampliação do próprio conceito de "cultura", de modo que essas políticas passem a contemplar não apenas as práticas artísticas, mas os modos de vida de maneira mais ampla. Tal discurso se fundamenta, em âmbito internacional, nos documentos produzidos pela Unesco desde os anos 1990, particularmente o relatório da Comissão Mundial de Cultura e Desenvolvimento, intitulado Nossa diversidade criadora (Cuéllar, 1997), e a Convenção sobre a Proteção da Diversidade e das Expressóes Culturais (Unesco, 2005). A orientação da ONU nessa matéria agendou o referido debate entre os países-membros, principalmente depois de ratificada a supramencionada Convençáo, em 2007. No Brasil - que teve, ele próprio, um papel protagônico na criação desses novos instrumentos na Unesco (Kauark, 2009; Córdula, 2016) -, a análise dos documentos programáticos produzidos pelo MinC nesse período permite confirmar a centralidade do valor "diversidade" em tais políticas. A preocupação subjacente a essa mudança discursiva é revelar os "brasis" e trabalhar com as múltiplas manifestações culturais em suas variadas matrizes étnicas, religiosas, de gênero, regionais etc. (Barbalho, 2007).

Uma das expressóes mais contundentes dessa nova orientação é a ampliação das cinco câmaras vinculadas à Fundação Nacional das Artes, a Funarte (artes visuais, música, teatro, dança e circo) para os dezoito colegiados setoriais abrigados sob o guarda-chuva do Conselho Nacional de Políti- ca Cultural (CNPC). Nessa nova estrutura - que abrange uma série de espaços participativos (comissóes, conselhos, conferências, fóruns etc.), criados durante a reestruturação do Ministério da Cultura, na gestão de Gilberto Gil (2003-2008) -, os representantes das áreas "clássicas" das políticas culturais dividem espaços e recursos com áreas emergentes (cultura alimentar, culturas populares, hip-hop, cultura LGBT etc.). Tal ampliação, que implicou reconhecer modalidades de mobilização sociopolítica em termos de produção simbólica, permitiu que interagissem com a política cultural oficial uma série de "fazedores de cultura" que extrapolavam a classe artística entendida de maneira restrita $(\mathrm{Mu}-$ niagurria, 2016).

Outro aspecto relevante a ser considerado é que os valores "diversidade" e "identidade" tornaram-se estruturantes das políticas públicas de cultura nesse momento, e o modo como tais valores foram incorporados a policy making, a partir dos mecanismos específicos de democracia participativa, não encontra correlatos nos períodos anteriores. Um marco importante desse processo foi a criação, em agosto de 2003, da Secretaria da Identidade e da Diversidade Cultural (SID), depois renomeada Secretaria da Cidadania e da Diversidade Cultural (SCDC), ${ }^{3}$ que abrangia, entre outras competências, a de "promover açóes que estimulam a convivência e o diálogo entre diferentes, a prática da interculturalidade, o respeito aos direitos individuais e coletivos, a proteção e o reconhecimento da diversidade simbólica e étnica” (Brasil, 2012). Esse órgão teve como um de seus desafios centrais estabelecer diálogos com grupos e redes culturais excluídos dos instrumentos de política de cultura (Mamberti, 2005). Entre as organizaçóes que primeiro atenderam ao chamado dessa secretaria para expressar suas demandas e criar políticas específicas estiveram o Movimento dos Trabalhadores Sem Terra (MST) e os Centros Universitários de Cultura e Arte (CUCA) da União Nacional dos Estudantes (UNE). Posteriormente, outras articulaçóes com movimentos organizados foram sendo estabelecidas. ${ }^{4}$

A preocupação pela inclusão de grupos minoritários (indígenas, culturas populares, LGBT, ciganos, pessoas com deficiência, crianças, idosos, povos de terreiro etc.) motivou também a criaçáo 
de um dos mais importantes programas da gestão petista no MinC, o Programa Nacional de Cultura, Educação e Cidadania - Cultura Viva, ${ }^{5}$ voltado para "os sem Estado", ou seja, os milhóes de brasileiros e brasileiras que não acessam os direitos básicos da cidadania, inclusive cultural. Para Célio Turino, coordenador do programa, na busca por um "Estado ampliado", o Cultura Viva promoveria o

[...] acesso aos meios de formação, criação, difusão e fruição cultural, cujos parceiros imediatos são agentes culturais, artistas, professores e militantes sociais que percebem a cultura não somente como linguagens artísticas, mas também como direitos, comportamento e economia (Turino, 2009, p. 15).

O nexo entre as mudanças políticas e as mudanças discursivas supracitadas se dá em dois níveis, que vale explicitar. Em primeiro lugar, a reabilitação do conceito ampliado de cultura nas políticas culturais ganha legitimidade em um contexto no qual a cultura se apresenta como "tecnologia gerencial de intervenção na realidade" (Ribeiro, 2014). Nesse sentido, é preciso considerar o êxito político de uma nova estrutura epistêmica na qual ela se coloca como recurso (Yúdice, 2004), lógica segundo a qual a produção simbólica pode (e deve) ser posta a serviço de causas não estritamente culturais - diminuir o desemprego, reaquecer a economia, recuperar áreas urbanas degradadas, reduzir a violência e os conflitos sociais etc. Em segundo lugar, o conceito de diversidade cultural, que por força da atuação da Unesco se difunde amplamente a partir dos anos 1990, passa a ser mobilizado não apenas por governos, mas também por empresas, associações e movimentos sociais, entre outros agentes. Para Nicolau Netto (2017), esse discurso da diversidade torna-se hegemônico em relação a outros dois - o da exceção cultural e o do multiculturalismo - que disputam, com ele, a legitimidade pela ordenação da diferença no período contemporâneo. Segundo o autor, é justamente esse discurso, calcado na arbitrariedade da produção da diferença, que permite ao movimento LGBT instaurar-se como produtor de uma cultura, uma vez que nem o discurso do multiculturalismo (fundamentado nas diferenças étnicas e religiosas), nem o da exceção cultural (pautado pela oposição entre cultura e mercado) dariam conta das articulaçóes mais pertinentes à especificidade de suas demandas.

No que se refere ao caso LGBT, sua inclusão nas políticas culturais sob o discurso da diversidade envolve duas operaçóes. A primeira delas é a atribuição de sentidos positivos a experiências afetivas, sexuais e sociais fortemente estigmatizadas, o que implica, entre outras coisas, culturalizar produçôes simbólicas diversas, como as Paradas do Orgulho, shows de drag queen, espetáculos de transformismo, além de outras expressôes (teatro, dança, artes visuais etc.) que tematizam a vivência das sexualidades dissidentes. ${ }^{6} \mathrm{Tal}$ conversão da produção simbólica LGBT em "cultura" é problemática, especialmente se comparada a outros casos, como o das culturas afro-brasileiras e indígenas, para os quais a promoção e a proteção de bens materiais e imateriais encontra guarida de longa data em discursos que preconizam a valorização das matrizes étnico-raciais que concorreram para a formação do povo brasileiro. Ou seja, nesses dois casos, a conversão de uma politica de reconhecimento em política cultural é objeto de controvérsias menos ancoradas em posicionamentos de cariz moral e religioso, ainda que isso eventualmente aconteça, sobretudo a partir dos posicionamentos de setores mais conservadores da sociedade. No caso que enfocamos aqui, em contrapartida, as práticas simbólicas da coletividade LGBT tendem a ser vistas como componentes de um padrão de comportamento desviante, que desperta variados graus de aversão na sociedade brasileira - da tolerância condicionada (por exemplo, o confinamento da expressão das sexualidades dissidentes aos espaços privados) à patologização e à criminalização, passando por variadas formas de violência simbólica e física, institucionalizadas ou não. ${ }^{8}$

A segunda operação - comum a outras áreas emergentes da política cultural oficial - é a reconversão da trajetória de militantes dos movimentos LGBT em produtores e agentes culturais, o que supóe a aquisição de vocabulários e repertórios necessários à interlocução com tais políticas. Essa reconversão, que implica o conhecimento aprofundado de mecanismos, trâmites e rituais característicos desse universo, pode ser considerada tanto causa como efeito da supramencionada culturalização, na medi- 
da em que o ingresso desses agentes nas instâncias de democracia participativa agenciadas pelo MinC redunda em seu reconhecimento e autorreconhecimento como produtores de cultura. Não se trata, é evidente, de um processo específico do campo das políticas culturais, uma vez que, também em outras pastas (direitos humanos, segurança, saúde, educação etc.) e em vários níveis (federal, estadual, municipal), a incidência política dessa coletividade teria implicado, segundo Facchini (2018, p. 319), um “aprendizado pelo movimento [LGBT] de linguagens que possibilitam o diálogo com instâncias estatais".

Vale destacar, a esse respeito, que o principal ponto de contato entre o Estado brasileiro e tais militantes havia sido, dos anos 1980 até aquele momento, o Ministério da Saúde, por meio de suas políticas relacionadas ao HIV/Aids, de modo que as "redes de solidariedade nascidas com o HIV/Aids foram constituindo-se em espaços políticos contra a LGBTfobia” (Caetano et al., 2018, p. 295). A resposta coletiva à epidemia foi, nesse sentido, um disparador da "aproximação entre setores de Estado e movimento [LGBT] na formulação, implementação e avaliação de políticas públicas e a consequente institucionalização do movimento" (Facchini, 2018, p. 319).

O Programa Nacional [de DST e Aids], ao longo de sua história, fez funcionar as políticas de Aids por meio da presença de inúmeros quadros que atuaram e conheciam profundamente os movimentos sociais LGBT e suas lideranças. [...] Foi por meio da Aids que as lideranças dos movimentos sociais LGBT no Brasil, sobretudo os gays, aprenderam a transitar nos jogos de elaboração de políticas públicas nas instâncias governamentais e legislativas (Caetano et al., 2018, p. 293).

Segundo Feitosa (2018), se nos anos 1980 o diálogo socioestatal se deu pela transferência de recursos aos grupos de ativismo para desenvolver projetos e pelos incentivos à organização do movimento para combater a epidemia de HIV/Aids, nos 1990, com a chamada reforma do Estado, muitos movimentos sociais se converteram em ONGs, tornando-se instituições parceiras do Estado. Com isso, o Ministério da Saúde passou a financiar encontros da militância, tendo inclusive contribuído para a realização das Paradas do Orgulho LGBT (Feitosa, 2018, p. 441). Nesses eventos, o apoio do Ministério mirava a população LGBT - sobretudo gays e transexuais - como foco de iniciativas de combate à Aids. Além do apoio financeiro propriamente dito, o Ministério (e outros órgãos de saúde, em nível estadual e municipal) encarregavam-se da distribuiçáo de preservativos, da entrega de folhetos informativos e da realizaçáo de testes rápidos de HIV durante o evento.

Esse é o principal precedente da participação LGBT na discussão, formulação, implementação e avaliação de políticas públicas no Brasil, bem como da criação das políticas culturais que aqui nos interessa analisar. Nesse sentido, pode-se dizer que a reestruturação do MinC durante os governos petistas favoreceu o ingresso de práticas LGBT nos meandros do aparelho estatal brasileiro por outras vias que não aquela pautada pela lógica do acesso do Estado a grupos sociais que, naquele caso, figuravam meramente como objeto de intervenção epidemiológica. ${ }^{9}$ Em vez disso, agora se tratava de considerar os produtores dessas manifestaçóes como sujeitos que produzem cultura e são capazes de participar da própria formulação da política cultural.

Tal processo ocorreu no momento em que se subverte parcialmente, no MinC, a articulação de interesses, práticas e discursos que tradicionalmente constitui a política cultural oficial no Brasil, qual seja, aquela que se dá entre uma elite política (a burocracia estatal), uma elite econômica (que financia direta ou indiretamente a cultura) e uma elite intelectual (que formula o "software" da política cultural). Esta última, convocada, contratada ou cooptada pelo Estado, havia servido até então de "mediadora" privilegiada entre os saberes gerados nos espaços institucionais (universidades, institutos históricos e geográficos etc.) e os saberes das populaçôes excluídas ou marginalizadas. No período analisado, a abertura de espaços de participação da sociedade civil na discussão e na formulação da política cultural desarranja esse esquema triangular ao introduzir no jogo uma quarta elite - uma espécie de "elite das minorias" (negros, indígenas, LGBTs etc.) - para dialogar com o Estado em pé de 
igualdade (ao menos teoricamente) com as elites do campo cultural (a chamada "classe artística").

Esse novo esquema que passa a vigorar no MinC - representado pela já mencionada transição das cinco câmaras da Funarte para os dezoito colegiados setoriais do CNPC - ganha maior inteligibilidade à luz de um conjunto mais amplo de mudanças que vieram a culminar com a criação da Política Nacional de Participação Social (PNPS), lançada em 2014 pelo governo Lula e tributária das experiências de gestão participativa que o Partido dos Trabalhadores havia ajudado a implementar desde os anos 1980. O funcionamento e a efetividade dessas experiências, que têm recebido atenção de uma ampla bibliografia (ver, por exemplo, Santos, 2003; Coelho e Nobre, 2004; Dagnino, 2004; Teixeira, 2010; Gurza Lavalle, 2011; Pires, 2011; Carlos et al., 2014), náo constituem o foco deste trabalho. Certo é que, pelo menos no caso do MinC e das instâncias participativas que ele pôs para funcionar (o CNPC, os colegiados setoriais, as conferências, os fóruns, os conselhos e as consultas públicas), tais mudanças significaram uma nova estrutura de oportunidades para que diversos grupos minoritários passassem a interagir de modo ora direto, ora indireto com o Estado brasileiro. ${ }^{10}$

Se os efeitos esperados de uma política cultural voltada à população LGBT são dar-lhe maior visibilidade e mitigar a estigmatização sofrida pelo grupo, uma questão mais ampla se coloca a partir do cenário supraexposto: até que ponto essas políticas permitem a tais grupos expressar suas demandas perante o Estado e contribui para criar condiçóes legítimas de inclusão cidadã desses sujeitos na vida pública do país? Se, por um lado, esse conjunto de problemas implica considerar a questáo do acesso aos direitos, que remete à relação dessas coletividades com a cidadania, o aspecto que mais diretamente se relaciona ao problema que aqui interessa perscrutar é o do acesso aos espaços de poder. Cumpre destacar, nesse sentido, o modo como a política cultural oficial se convertera em um locus, entre outros, onde se disputava o valor intrínseco desses grupos, que ali travavam embates pela legitimidade de suas práticas e seus modos de vida.

\section{Identidade, diversidade e diferença: o MinC e a cultura LGBT}

Para compreender a produção dessas políticas culturais LGBT no Ministério da Cultura, analisamos um corpus formado pelos editais lançados pelo MinC entre 2005 e 2009, direcionados à comunidade LGBT (ver Tabela 1). A análise dos referidos editais constitui uma primeira via de acesso às relaçóes entre o MinC e a SID/SCDC e os membros da coletividade LGBT envolvidos na elaboração e na execução dessas políticas. Tais documentos permitem colocar em questão o modo como essas relaçôes expressaram de-

Tabela 1

Editais do Ministério da Cultura Voltados à Cultura LGBT (2005-2009)

\begin{tabular}{lll}
\hline Ano & Edital & Recursos totais (em reais)* \\
\hline 2005 & Edital de Divulgação no 1: Parada do Orgulho GLBT & $600.000,00$ \\
\hline 2006 & Edital no 1: Concurso “Cultura GLTB” & $1.200 .000,00$ \\
\hline 2007 & Edital de Divulgação no 2: Cultura GLBT & $1.000 .000,00$ \\
\hline 2008 & Edital no 9: Paradas do Orgulho GLBT & $810.000,00$ \\
\hline 2008 & Edital no 10: Cultura GLBT & $936.000,00$ \\
\hline 2009 & Edital no 1: Prêmio Cultural LGBT & $1.242 .000,00$ \\
\hline
\end{tabular}

Fonte: Elaboração própria com base nos documentos disponibilizados no site do MinC.

* Os valores correspondem ao total do repasse previsto nos respectivos editais. Náo equivalem, necessariamente, aos valores efetivamente alocados após a fase de seleção dos projetos. 
terminadas demandas simbólicas e trunfos politicos dos "fazedores de cultura" LGBT no Ministério.

A análise recorreu ao suporte da Teoria do Discurso (TD) desenvolvida por Laclau e Mouffe (2010), com desdobramentos contemporâneos (Mendonça e Rodrigues, 2014; Howarth, Norval e Stavrakasis, 2009). Para os fins deste artigo, nos deteremos em algumas das indicaçóes da obra de Laclau e Mouffe, publicada originalmente em 1985. O elemento central da reflexão dos autores é o conceito de hegemonia, a partir de um diálogo com a tradição marxista, especialmente Antonio Gramsci.

Para Laclau e Mouffe, uma formação social pode estar composta de vários pontos nodais hegemônicos, que irradiam múltiplos efeitos nos espaços políticos, sociais e culturais. Por isso, não há nem total autonomia, nem total subordinação, e um processo de autonomização - por exemplo, de um movimento social - não resulta de um efeito estruturante, mas de uma prática articulatória. Assim, defendem, a autonomia é uma forma de construção hegemônica. Os movimentos sociais como sujeitos políticos estão, assim, submetidos à flutuação de seus significantes, e o contexto que permitiu as condiçóes discursivas de sua autonomização pode ser subvertido. Para os autores, a questão de maior potência colocada pelos novos movimentos sociais não é se (e como) eles se distinguem dos movimentos classistas, mas o fato de expressarem a crescente difusão da conflitualidade social, marca da contemporaneidade.

Outra categoria importante é a de articulação, que é a "construção de pontos nodais que fixam parcialmente o sentido" (Laclau e Mouffe, 2010, p. 154). ${ }^{11} \mathrm{O}$ discurso é entendido, então, como a totalidade que resulta do conjunto de práticas articulatórias, conjunto que, por sua vez, constitui e organiza as relaçôes sociais. $\mathrm{O}$ social é articulação porque não tem essência, e a necessidade só existe como esforço parcial de pôr limites à contingência. As regularidades discursivas são, portanto, formas relativas e precárias de fixação que acompanham a instauração de certa ordem no discurso, "e o caráter parcial dessa fixação procede da abertura do social, resultante, por sua vez, do constante desbordamento de todo discurso pela infinitude do campo da discursividade" (Laclau e Mouffe, 2010, p. 154). "O discurso", argumentam os autores, "se constitui como intento por dominar o campo da discursividade, por deter o fluxo das diferenças, por constituir um centro", e "os pontos discursivos privilegiados desta fixação parcial, os denominaremos pontos nodais" (p. 152).

Para Laclau e Mouffe, o limite da totalidade discursiva é a existência de outros discursos, que criam suas condiçôes de vulnerabilidade: todo discurso está sujeito a desestabilizaçôes de seu sistema de diferenças como resultado da atuação de outras articulações discursivas fora dele. Assim, uma formação discursiva não existe como positividade dada e delimitada; sua lógica relacional é incompleta e afetada pela contingência. Entendido como sistema de momentos - ou seja, de posiçóes diferenciais -, o discurso só é possível como limitação parcial de um excesso de sentido que o subverte. Tal lógica, que desarticula a estrutura discursiva, requer a proliferação de sentidos, a polifonia.

Outro aspecto importante da teorização de Laclau e Mouffe (2010, p. 168) é a noção de antagonismo, que "constitui os limites de toda objetividade - que se revela como objetivação, parcial e precária". Por isso, o antagonismo é também a "experiência" do limite do social. Tal lógica das diferenças coloca ao analista do social a necessidade de considerar que o social se constitui de múltiplos antagonismos possíveis. O que se conclui, nesse ponto, é que, às relaçóes sociais mais instáveis e com menor definição das diferenças, correspondem mais pontos de antagonismo. Já a produção de "efeitos de fronteira”, condição de expansão dos antagonismos, não se funda numa separação evidente e dada (como seria, supostamente, a de classes) e se converte no primeiro dos problemas propriamente políticos, a partir da construção das identidades que se enfrentam antagonicamente. Isto, por sua vez, amplia o campo das práticas articulatórias, posto que toda fronteira é ambígua, instável e está sempre em deslocamento. Ora, é no campo das práticas articulatórias que a hegemonia emerge: em um sistema de identidades fixas, não há possibilidades para práticas hegemônicas; onde as diferenças excluem qualquer significado flutuante, não há espaço para articulaçóes. A hegemonia precisa da abertura e da incompletude do social para acontecer.

Nessa perspectiva, a reproduçáo social se defronta com condiçóes em constante mudança, o 
que repóe, a todo momento, novos sistemas de diferenças e, por consequência, novas articulações. Sendo improvável a fixação das diferenças, cada identidade social torna-se o ponto nodal de múltiplas práticas articulatórias, muitas delas antagônicas entre si. Disso resulta a impossibilidade de "chegar a uma completa interiorização que feche totalmente a brecha entre articulante e articulado", do mesmo modo que se torna impossível que a identidade separada da força articulante náo se transforme: "ambas estão submetidas a um processo de subversão e redefinição constantes”, pois

[...] uma formação hegemônica abarca também o que se lhe opóe, na medida em que a força opositora aceita o sistema de articulaçóes básicas de dita formação como aquilo que ela nega, mas o lugar da negociação é definido pelos parâmetros internos da própria formação (Laclau e Mouffe, 2010, pp. 182-183).

A partir das consideraçóes supracitadas, podemos localizar, tendo como referência o campo discursivo em torno da coletividade LGBT, uma formação discursiva, ou seja, uma prática articulatória a constituir e organizar as relaçôes da referida coletividade no (e com o) MinC. Podemos entendê-la como uma nova frente de disputa em relação com o Estado ${ }^{12}$ (e dentro dele) em torno de valores voltados à experiência social, cultural e política das sexualidades dissidentes. Essa forma institucional de atuação se inicia na gestão do Ministro da Cultura Gilberto Gil, com a criação, pela Portaria n ${ }^{\circ}$ 219, em julho de 2004 (ver Quadro 1), do Grupo de Trabalho (GT) de Promoção da Cidadania GLTB $^{13}$, coordenado pela SID. O GT tinha como objetivo "elaborar um plano de fomento e preservação às produçôes artísticas e aos valores culturais e sociais, decorrentes da população homossexual brasileira" (grifo nosso). Essa portaria é o primeiro dos "atos de Estado" - "atos políticos que têm pretensóes de exercer efeitos no mundo social" (Bourdieu, 2014, p. 27) - que o MinC realiza no que diz respeito à conformação da cultura LGBT. Ao longo dos anos seguintes, como veremos, serão lançados outros desses atos, como editais, comissóes e portarias. Por

\section{Quadro 1}

\section{Marcos Relacionados à Política LGBT no Ministério da Cultura}

\begin{tabular}{|c|c|}
\hline 2002 & Programa Nacional de Direitos Humanos 2 (Gestão FHC)* \\
\hline 2003 & $\begin{array}{l}\text { Início da gestão Gilberto Gil no MinC } \\
\text { Criaçáo da Secretaria da Identidade e da Diversidade Cultural (SID) }\end{array}$ \\
\hline 2004 & $\begin{array}{l}\text { Criação do Grupo de Trabalho de Promoçãa da Cidadania GLTB } \\
\text { Criaçáo do Programa Brasil sem Homofobia }\end{array}$ \\
\hline 2005 & Convenção sobre a Proteção da Diversidade e das Expressóes Culturais \\
\hline 2006 & Ratificação da Convenção da Diversidade pelo Congresso Nacional \\
\hline 2007 & Criação do Programa de Fomento a Projetos de Combate à Homofobia do MinC \\
\hline 2008 & $\begin{array}{l}\text { Fim da gestâo Gilberto Gil } \\
\text { I Conferência Nacional de Gays, Lésbicas, Bissexuais, Travestis e Transexuais }\end{array}$ \\
\hline 2009 & $\begin{array}{l}\text { Plano Nacional de Promoção da Cidadania e Direitos Humanos de Lésbicas, Gays, Bissexuais, Travestis e } \\
\text { Transexuais } \\
\text { Programa Nacional de Direitos Humanos } 3\end{array}$ \\
\hline 2010 & $\begin{array}{l}\text { Criação da Coordenadoria Nacional de Promoção dos Direitos de LGBT na SDH } \\
\text { Implantaçáo do Conselho Nacional de Combate à Discriminaçáo (CNDC) }\end{array}$ \\
\hline
\end{tabular}

Fonte: Elaboração própria com base nos documentos disponibilizados no site do MinC.

* Ao contrário da primeira versão do PNDH, aqui a questão LGBT e o combate à homofobia aparecem expressamente. 
detrás de todos eles, encontram-se "agentes dotados de uma autoridade simbólica, a que se seguem efeitos" (Bourdieu, 2014, p. 27). A constituição do GT, bem como das comissóes julgadoras dos editais, remete a dois outros atos, ou a uma dupla nomeação: (1) de um "conjunto de pessoas reconhecidas como habilitadas, socialmente designadas para cumprir determinada função" e (2) de um "problema público" (Bourdieu, 2014, p. 47).

O fato de ter sido a SID a assumir a coordenação do GT é um primeiro indício em direção à hipótese de que houve uma tentativa de amenizar o antagonismo (aceitação/valorização versus aversão/intolerância às sexualidades dissidentes ${ }^{14}$ ) que traça o limite de constituição do campo discursivo LGBT. Trata-se, aqui, da ambiguidade do efeito de fronteira, que, na impossibilidade de definir claramente as posiçóes de sujeito, vacila entre afirmar a diversidade cultural, reconhecendo a cultura LGBT, e o direito à liberdade de orientação sexual e à igualdade no trato social, ainda que em uma chave cultural(izante).

Como já dito, a matriz discursiva do SID/ SCDC remetia ao debate sobre diversidade cultural conduzido no âmbito da Unesco, sendo um de seus principais documentos o relatório final da Comissão Mundial da Cultura e Desenvolvimento, intitulado, sugestivamente, Nossa diversidade criadora. Nesse documento, afirma-se o "sentido de tolerância, respeito e satisfação em face da pluralidade de culturas" (Cuéllar, 1997, p. 71). Os três valores aí enunciados - tolerância, respeito e satisfação - estão em relação direta com a noção de "cultura de paz”, que também se torna central para as diretivas da Unesco nesse período, como discutiremos adiante. E, tal como indica o nome, a SID foi o locus privilegiado de produção de discursos em torno da identidade e da diversidade. $\mathrm{Na}$ análise desses discursos, é possível observar que a diversidade não se torna uma síntese, como no recurso à mestiçagem na lógica integradora dos governos militares, nem se reduz à diversidade de ofertas em um mercado cultural globalizado, lógica operante na gestão de Francisco Weffort, na presidência de Fernando Henrique Cardoso. Para o secretário da SID, Sérgio Mamberti, o órgão teria três desafios centrais:
[...] a) participar nos debates internacionais em torno da diversidade cultural; b) promover o melhor entendimento do conceito de diversidade cultural no contexto da cultura brasileira e trabalhar de maneira transversal aos segmentos governamentais e da sociedade civil; c) estabelecer diálogos com grupos e redes culturais representativos da diversidade cultural brasileira ainda excluídos do acesso aos instrumentos de política pública de cultura e contribuir para o aperfeiçoamento dos mecanismos de proteção e promoção da nossa diversidade cultural (Mamberti, 2005, p. 13).

$\mathrm{Na}$ avaliação de Juca Ferreira, então secretário executivo do Ministério, haveria, na instituição, uma nova visão de cultura com viés antropológico, que valorizaria todos os modos de expressão. Disso derivaria a necessidade do MinC de chegar às culturas populares, às etnias, aos grupos etários, aos trabalhadores, dando "a importância devida a essas expressões culturais, conferindo-lhes o justo valor cultural, preenchendo lacunas e reparando erros" (Ferreira, 2005, p. 19). Com o governo Lula, tem-se, portanto, uma reavaliaçáo do que seria a identidade nacional brasileira, que aponta para o pluralismo e a incorporação de expressóes culturais historicamente excluídas. A diversidade não resulta mais em uma síntese - pelo contrário, esta cede à diversidade e se multiplica em identidades. Há, ainda, a cobrança do papel fundamental do Estado como elaborador e executor de políticas culturais.

No entanto, mesmo fazendo referências às diferentes culturas, a gestão do Ministro Gilberto Gil não conseguiu romper com a busca de uma harmonia entre os brasis. Não se coloca na sua radicalidade (no sentido de raiz e não de sectarismo) a questão da identidade em seu conflito com a diferença. A relação identidade/diversidade está na base das manifestaçōes culturais que funcionam como referências identitárias, muitas vezes efêmeras, para os vários grupos sociais. Os sentidos assumidos, portanto, não sáo fixos, e sim processuais, e a identidade deixa de ser um fato consumado para ser uma produção.

Além disso, a diversidade não dá conta dos conflitos entre as culturas. Seu pressuposto é o da convivência harmoniosa, da fraternidade entre os 
povos do ideário iluminista. Como indica a apresentação de Gilberto Gil ao Seminário Diversidade Cultural Brasileira:

Sáo fundamentais o respeito, a valorização e $o$ convivio harmonioso das diferentes identidades culturais existentes dentro dos territórios nacionais [...] podemos e devemos reconhecer e valorizar as nossas diferenças culturais, como fator para a coexistência harmoniosa das várias formas possiveis de brasilidade (Gilberto Gil, 2005, p. 7; grifos nossos).

A essa perspectiva universalista e liberal, ou de cariz holístico, segundo o discurso do Ministro, cabem as observaçóes críticas de Tomaz Tadeu da Silva:

$\mathrm{Na}$ perspectiva da diversidade, a diferença e a identidade tendem a ser neutralizadas, cristalizadas, essencializadas. São tomadas como dados ou fatos da vida social diante dos quais se deve tomar posiçôes. Em geral a posição socialmente aceita e recomendada é de respeito e tolerância para com a diversidade e a diferença. Mas será que as questóes da identidade e da diferença se esgotam nessa posição liberal? (Silva, 2000, p. 73).

É nesse solo, portanto, que o GT começou a funcionar no MinC. Após seus encontros ao longo de 2004, deliberou-se como prioridade de atuaçáo do Ministério apoiar as "Paradas Gay", avaliadas pelos integrantes do grupo como um "evento de visibilidade massiva de conscientizaçáo cidadá, manifestação cultural e afirmação do direito à expressão de orientaçáo sexual e da cultura de paz" (Brasil, s.d.). ${ }^{15}$ Dessa forma, o MinC lançou, em março de 2005, o Edital de Divulgação no 1 : Parada do Orgulho GLBT (Brasil, 2005).

$\mathrm{O}$ apoio a essas manifestaçóes torna-se, portanto, o objeto do primeiro edital, ou seja, da primeira açáo específica do Ministério para a cultura LGBT. O edital convocou a apresentarem propostas "organizaçôes/instituiçôes que desenvolvam açôes de caráter cultural e social voltadas para a afirmaçáo da identidade de gays, lésbicas, transgêneros e bissexuais - GLTB, sem fins lucrativos, legalmente constituídas" (Brasil, 2005). Para a seleçáo das propostas, o MinC constituiu uma Comissão Julgadora com pessoal oriundo do órgáo e por pareceristas ad hoc, indicados pelo Secretário da SID, presidente da Comissão.

Entre os critérios considerados pela Comissão no momento de avaliação dos projetos submetidos, estavam: a "inclusão de gays, lésbicas, transgêneros e bissexuais nas açóes, de modo a garantir a visibilidade de cada público e suas especificidades"; o "caráter exemplar e inovador dos objetivos"; a "realizaçấo de açôes de informação, conscientização e mobilizaçáo da populaçáo em geral de modo a divulgar valores de respeito à diversidade humana e cultural"; a "realização de açôes que garantam a visibilidade das diversas manifestaçôes culturais, de modo a estimular a participação cultural e cidadã da população beneficiada, reconhecendo a sua história, seus bens culturais e sociais, inclusive do aproveitamento de elementos das linguagens artísticas e das expressóes da cultura popular"; a previsão de "uma ação social e cultural efetiva junto à comunidade a que estão vinculados"; e a "integração das comunidades GLTBs" (Brasil, 2005). Inclusão, reconhecimento e visibilidade - sintagmas de ampla circulaçáo nos documentos programáticos no movimento LGBT, e que denotam algumas de suas principais demandas históricas - são, assim, incorporados desde o início ao aparato discursivo das açóes do MinC voltadas a essa comunidade. Complementarmente, vale notar a presença da ideia de "integração", que, ecoando velhas e novas políticas de gerenciamento da diferença, esbarra no problema da assimilaçáo (social) e da cooptaçáo (política) das dissidências.

Para o ano seguinte, o GT decidiu ampliar o escopo das atividades apoiadas e lançou, em maio, o Edital no 1: Concurso "Cultura GLTB", inserido no Programa de Trabalho "Fomento a Grupos e Redes da Diversidade Cultural Brasileira", que visava a "o fomento e desenvolvimento dos grupos e redes responsáveis pela produçấo das expressōes culturais da diversidade humana” (Brasil, 2006).

Nota-se que é um edital mais amplo do que o anterior em termos de público-alvo, e mais complexo no que diz respeito à concepção de seus objetivos. Quanto ao público, o edital convocava "as 
organizaçóes/instituiçóes de direito privado, sem fins lucrativos, que desenvolvam ações de caráter cultural voltadas para a afirmação da identidade de gays, lésbicas, transgêneros e bissexuais - GLTB" e apoiava "projetos culturais e artísticos de afirmação do direito e expressão de orientação sexual" nas diversas linguagens artísticas (teatro, dança, audiovisual, música, literatura etc.), além de outras expressóes culturais (cultura popular, cultural digital, patrimônio material e imaterial), nos mais diferentes formatos (paradas, shows, debates, encontros, seminários etc.), contanto que "possibilitem uma efetiva troca de experiências e desdobramentos, com visibilidade nas comunidades beneficiadas" (Brasil, 2006).

No que diz respeito aos seus objetivos e diretrizes, trata-se de "promover a difusão da diversidade cultural, com ênfase na qualidade, na diversidade e na visibilidade de grupos formadores da cultura brasileira" (Brasil, 2006). Tal objetivo geral se concretizava em objetivos específicos:

[...] fortalecer as organizaçóes socioculturais GLTB; proporcionar visibilidade às manifestaçóes desenvolvidas por essas organizaçóes; promover a interação social entre diversos grupos e suas manifestaçóes, como forma de incentivar a troca de experiências e a convivência pacífica; construir um Brasil mais justo, onde todas as manifestaçôes socioculturais e artísticas possam ter o seu espaço e valores garantidos (Brasil, 2006).

Os agentes responsáveis pela política voltada à cultura LGBT ampliaram o escopo de atuação, não se restringindo às Paradas do Orgulho, objeto único do edital anterior. $\mathrm{O}$ alargamento das fronteiras de presença e atuação dessa expressão cultural poderia ter levado a uma ampliação das zonas de confronto entre os discursos antagônicos (aceitação/valorização versus aversão/intolerância às sexualidades dissidentes), por capitalizar, simbólica e materialmente, um dos lados contendores. Ou seja, na análise do edital, o antagonismo poderia estar expresso de alguma forma. Contudo, isto não ocorreu. Tal como no anterior, destaca-se aqui o esforço por uma cultura de paz que, se pressupóe um estado de guerra ou conflito, não o nomeia nem qualifica. Essa ênfase é reforçada pelo recurso às noçóes de "troca" e "interaçáo", que pressupóem a existência de um ambiente de abertura empática da população brasileira às manifestaçôes culturais LGBT, uma abertura que pudesse promover o efetivo compartilhamento de concepçóes de mundo entre os grupos.

Em maio de 2007, o MinC lançou o Edital de Divulgação no 2: Cultura GLTB (Brasil, 2007a), que mantinha, basicamente, o formato do ano anterior. Entre as poucas modificaçóes, cumpre destacar a nova composição da Comissão de Avaliação. Em 2006, o edital fixava apenas que a Comissão seria constituída pelo MinC por meio da SID, a quem competia sua presidência. No Edital no 2, a Comissão foi formada, além dos integrantes do MinC, por membros indicados pelo Ministério da Saúde e pela Secretaria Especial dos Direitos Humanos, além de um especialista na área cultural.

A presença de agentes oriundos do campo da saúde e do campo dos direitos humanos na execução da política cultural voltada à população LGBT introduz posiçôes de sujeito com potencial para provocar instabilidades semânticas à acomodação proporcionada pelo discurso da diversidade nos momentos de deliberação das propostas selecionadas. ${ }^{16}$ No primeiro caso, trata-se da (re)inserção de uma institucionalidade que havia tradicionalmente dialogado com os movimentos de militância LGBT na formulação das políticas de combate e prevenção ao HIV/Aids, ou seja, a presença de um regime discursivo onde a coletividade LGBT é concebida como objeto de intervenção epidemiológica. No segundo, tal como discutiremos adiante, trata-se de realocar a execução da política cultural num quadro mais amplo de combate à violência e à discriminação. Ademais, esse duplo enquadramento (saúde/ violência) recoloca a questão da política cultural como locus onde a cultura se póe a serviço de outras finalidades que não aquelas estritamente relacionadas ao acesso à produção e fruição da produção simbólica (em um caso, redução da epidemia; em outro, redução da conflitividade social). À valorização da produção simbólica LGBT como positividade, como característica a ser reafirmada, se acrescenta aquilo que é sua negatividade - sua situação vulnerável em termos de direitos -, a ser superada. 
Esse enquadramento dos direitos humanos na política cultural para o segmento LGBT se consolida em julho do mesmo ano, quando o MinC lança a Portaria no 32 criando o Programa de Fomento a Projetos de Combate à Homofobia, cujo objetivo era "promover a cidadania homossexual, combater a violência e a discriminação contra gays, lésbicas, transgêneros e bissexuais", por meio

[...] do apoio e estímulo a projetos culturais GLTB, Paradas do Orgulho GLTB, e açóes que visem ao desenvolvimento, ao fortalecimento, à promoção e à divulgação das expressôes artísticas da população brasileira GLTB (Brasil, 2007b).

O aspecto a ser destacado aqui é que essa portaria nomeia a existência da violência e da discriminação sofrida pela população LGBT, trazendo novos elementos na prática articulatória dos agentes LGBT no âmbito do Estado, mais especificamente no MinC. A redação do documento sinaliza, assim, a presença de posiçóes de sujeito outras, comprometidas com questóes não contempladas pelo discurso pacificador da diversidade.

No dia 15 de maio do ano seguinte, o MinC (Brasil, 2008a) volta a lançar edital de apoio específico às Paradas de Orgulho GLBT (Edital no 9), mantendo também o edital (Brasil, 2008b) mais amplo de apoio à cultura GLBT (Edital no 10). É relevante observar que, no texto de introdução, ambos os editais afirmam estar em consonância com os artigos $1^{\circ} ; 2^{\circ}, 7^{\circ}$ e 11 da Convenção sobre a Proteção e Promoção da Diversidade das Expressóes Culturais, da Unesco. Nesse sentido, tais documentos posicionam-se em conformidade com o universo discursivo da "diversidade". Por outro lado, tais editais também integravam o Programa Brasil sem Homofobia, da Secretaria Especial de Direitos Humanos, e o Programa de Combate à Violência e à Discriminação contra GLBT e de Promoção da Cidadania Homossexual. A filiação desses editais a tais programas traz, pela primeira vez, de forma explícita, a dimensão antagônica para o campo discursivo em análise. Embora não possamos dizer que tais significantes (homofobia, violência sexual, discriminação sexual) sejam oriun- dos de formaçóes discursivas propriamente externas (afinal, direitos humanos e promoção da cidadania são elementos constitutivos do discurso da diversidade), sua presença nos editais do MinC náo deixa de criar desestabilizaçóes, possibilitando outras articulações no campo da discursividade LGBT. ${ }^{17}$

Outra mudança importante dos editais, em relação aos anteriores, diz respeito à composição da Comissão de Seleção. Se, como vinha ocorrendo, o processo era presidido pela SID, com participação de membros do MinC, bem como de "profissionais de notório saber e de reconhecida atuação na área cultural", pela primeira vez aparece um agente ligado diretamente ao público-alvo: os "representantes das comunidades GLBT". E mais: esses representantes deveriam ser indicados por entidades ligadas a essas comunidades. Faz-se presente, aqui, a recomendação do artigo 11 da referida Convenção da Unesco, o qual advoga pela participação ativa da sociedade civil na proteção e promoção da diversidade de expressóes culturais.

A nomeação da violência física e simbólica perpetrada à comunidade LGBT no texto do edital e a autorização (empowerment) a agentes dessa comunidade para que participem da seleçáo das propostas são reforçadas pelos critérios considerados no processo seletivo, que privilegiavam, entre outros valores, a parceria entre as organizaçóes LGBT, o respeito à diversidade e o combate à homofobia e à transfobia. No caso do Edital no 10 , há um objetivo que compóe esse universo, que é o de "Apoiar iniciativas de afirmação de orientação sexual, identidade de gênero e da cultura de paz, que contribuam para o combate à homofobia e transfobia" (Brasil, 2008b). Observa-se ali uma tensão entre a afirmação harmonizadora da diversidade - proporcionada por uma possível cultura de paz - e o reconhecimento das diferenças sexuais, que resultam em clivagens simbólica e fisicamente violentas.

Salvo alteraçôes mínimas, as diretrizes dos editais de 2008 se consolidariam na edição de 2009, último ano em que ocorreu o lançamento de documentos desse tipo. Ali também está presente a vinculação tanto aos repertórios de diversidade da Unesco como aos programas federais de combate à homofobia. As poucas mudanças de um ano a outro, por sua vez, reforçaram a supracitada tensão: 
introduz-se, nos critérios de seleção, a valorização de ações culturais que promovam a conscientização sobre o respeito ao direito à livre orientação e expressão sexuais, bem como aquelas que transmitam informaçóes afirmativas e positivas à comunidade.

\section{Apontamentos conclusivos}

A análise do corpus permitiu uma primeira abordagem ao modo como o movimento LGBT agendou a política cultural em um GT temático criado no MinC. Essa política se efetivou especialmente por meio de editais, seja os de apoio às Paradas do Orgulho, seja os de promoção da cultura LGBT considerada de modo mais amplo. O que constatamos, ao analisar esses documentos, é um processo que vai da inclusão, da visibilidade, do respeito à diversidade sexual (no primeiro edital de 2005), passa pela afirmação do direito e expressão sexual e da cultura de paz (a partir do edital de 2006), e chega à explicitação do combate à homofobia, à transfobia, à violência sexual e à discriminação (nos editais de 2008 e 2009).

Assim, é possível argumentar que os editais buscaram administrar os potenciais conflitos entre discursos antagônicos (aceitação/ valorização versus aversão/intolerância às sexualidades dissidentes), afirmando a diversidade e a cultura de paz. A recorrência dessas duas expressóes - formas positivadas de gerir discursivamente os temas da discriminação e da violência - nesses documentos parece decorrer das diretivas às quais a ONU e seus organismos passaram a dar prioridade desde os anos 1990 e principalmente nos anos 2000. No primeiro caso, do conceito de diversidade, os editais não faziam mais do que ecoar as diretivas da supramencionada Convenção de 2005 da Unesco. Quanto à cultura de paz, vale lembrar que a ONU - que desde o início dos anos 1990 agenda o tema - instituiu os anos de 2001 a 2010 como a "Década Internacional para uma Cultura de Paz e Não Violência para com as Crianças do Mundo" (ONU, 1999a; 1999b), programa que a Unesco se encarregou de implementar. Nessa perspectiva, esses documentos do MinC mostram forte alinhamento com o tom hegemonicamente conciliatório das agendas que essas organizaçóes internacionais se incumbem de espraiar por seus Estados-membros. ${ }^{18}$

No entanto, retomando Laclau e Mouffe (2010), uma formação discursiva não é uma positividade delimitada e suturada: afetada pela contingência e pela sobredeterminação, sua articulação é sempre instável. Ora, o excesso de sentidos subverte a lógica da diversidade (em que prevalece a busca do consenso) e impóe elementos da lógica da diferença (que pressupóe conflito), próprios ao campo da discursividade LGBT. Daí provém a presença do combate à violência física e simbólica quando se desejava apenas a posição afirmativa e inclusiva a partir do significante "humanidade", em sua lógica liberal universalista.

Ainda que se postule a especificidade da dimensão discursiva do problema que aqui nos interessa, o entendimento mais apurado sobre os resultados dessa prática articulatória requer a análise de como se deram as práticas dos agentes dos movimentos LGBT e dos agentes estatais nos espaços de discussão e de decisão no interior do MinC. Em outras palavras, interessaria interrogar de que modo se deu o acesso desses agentes a esse espaço de poder e a consequente culturalização da política de reconhecimento. A compreensão de tais articulaçóes só se torna possível se entendermos o Estado não como um bloco monolítico, um instrumento de reprodução das classes e valores dominantes, mas como um metacampo, para onde convergem todos os outros campos e, portanto, como espaço privilegiado para o surgimento e a expressão pública de antagonismos entre diferentes posições, investimentos e capitais (Bourdieu, 2014).

As experiências de gestão participativa das quais as políticas culturais analisadas são tributárias e as oportunidades de diálogo socioestatal que tais experiências ensejam parecem explicar, pelo menos em parte, as mudanças discursivas dos editais aqui considerados: os rearranjos textuais, ainda que sutis, mostram a incidência de outras posiçóes do sujeito, que produzem tensionamentos semânticos e descentram a diversidade cultural como palavra-chave da política cultural LGBT. Interessaria, nesse sentido, situar as posiçóes e as tomadas de posição dos policy makers oriundos do campo cultural e operadores do conceito de diversidade cultural 
e dos agentes externos a esse campo e que trazem para dentro do MinC, por meio do GT, os antagonismos enfrentados pela comunidade LGBT. Novas questôes se colocam a partir daqui: qual teria sido o teor dos debates nesses dois grupos dentro do $\mathrm{Mi}$ nistério? De que maneira tais debates se relacionam com a paulatina introduçáo nos editais daquele antagonismo básico (aceitação/valorização versus aversão/intolerância às sexualidades dissidentes) ao campo LGBT, expresso em práticas como homofobia, violência física e discriminação sexual?

Tais questionamentos, que surgem do nosso interesse por compreender os conflitos derivados da intersecção entre a política cultural e as políticas de reconhecimento das sexualidades dissidentes, se revestem de inegável importância e atualidade. No momento em que este trabalho de pesquisa estava sendo concluído, uma série de incidentes de censura à arte ocupou espaço no debate público brasileiro: o fechamento da exposição Queermuseu no Santander Cultural, em Porto Alegre (RS), em setembro de 2017; no mesmo mês, a apreensão pela polícia de obra exposta no Museu de Arte Contemporânea de Campo Grande (MS) e o cancelamento da peça de teatro $O$ Evangelho segundo Jesus, Rainha do Céu, no SESC Jundiaí (SP). No cenário legislativo, um fato a ser destacado é a vitória da Frente Parlamentar Evangélica da Câmara do Distrito Federal, que, em outubro de 2017, pediu a anulação de uma portaria da Secretaria de Cultura que estabelecia uma política específica para a comunidade LGBTI, "em respeito à família brasiliense". Esses episódios, ${ }^{19}$ que tiveram grande repercussão, demonstram que a produçáo cultural se torna uma arena importante não só para a expressão das demandas LGBT por reconhecimento e por direitos, mas também para setores que se opóem frontalmente a tais demandas.

Todos esses acontecimentos, motivados pela ação organizada de setores da sociedade civil, da classe política e do Poder Judiciário, trouxeram à tona controvérsias que contrapóem o direito à liberdade de criação artística e as demandas societárias de cariz moral e religioso. $\mathrm{O}$ modo como tais controvérsias se infiltram no seio da política cultural (seja ela pública, privada ou do terceiro setor), moldando as decisóes dos policy makers e a ingerência de interesses alheios na sua formulação, merece um lugar nos debates das ciências sociais, particularmente num momento histórico em que a própria continuidade das políticas aqui analisadas encontra-se comprometida em função de políticas de ajuste fiscal, do refluxo participativo em curso desde o golpe de 2016 e pelo giro conservador nas últimas eleiçóes presidenciais e legislativas de 2018. Em outro nível de análise, tais questóes atualizam, sob nova roupagem, as velhas contendas sobre a definição e abrangência da "arte" e da "cultura", disputas por legitimidade que, em última instância - e particularmente quando envolvem a produção simbólica de grupos minoritários -, remetem aos conflitos sociopolíticos que contrapóem interesses pela ampliação de direitos e pela manutenção de privilégios.

\section{Notas}

1 Usamos a sigla LGBT em referência à categoria êmica mais corrente atualmente no Brasil para referir-se às expressóes dissidentes de sexualidade e gênero (ou seja, situadas fora dos parâmetros cis e heteronormativos). Ela abrange também outras denominaçóes, como Gay, GLBT, GLTB, LGBTT etc., que são mencionadas no texto conforme apareçam na documentação analisada. Para uma síntese do processo de constituição da sigla, particularmente na interação socioestatal do movimento no Brasil, ver Aguiaao (2014, p. 75). Usamos os termos "coletividade" e "populaçáo" LGBT para referir-nos a todos aqueles que podem se reconhecer a partir dessa categoria tal como construída por um conjunto mais restrito de "militantes" ou membros do "movimento" LGBT - distinção que, por exemplo, Facchini (2009) assinala com os termos "campo" e "arena” LGBT. Por fim, recorremos ao uso de aspas para destacar conceitos, categorias e sentenças tal como elas aparecem nos documentos analisados e na bibliografia consultada.

2 Sobre a constituição da coletividade LGBT como sujeito político, ver Simóes e Facchini (2009). Sobre a trajetória da população LGBT como sujeito de direitos no Brasil contemporâneo, ver Aguião (2014).

3 Doravante referimo-nos a esse órgáo pela sigla SID, enfocando o período em que vigorou tal denominação, ou SID/SCDC, quando remete-se à sua existência tanto pretérita como atual. 
4 Um relato endógeno da construção da SID pode ser consultado em Córdula (2016).

5 A principal ação do Programa Cultura Viva é o Ponto de Cultura, com o qual, através de um edital de seleção pública, o Minc apoia projetos culturais promovidos pela sociedade civil.

6 Usamos a expressão "sexualidades dissidentes" no sentido de abranger expressóes de sexualidade e gênero que não se enquadram nos parâmetros da cisnormatividade e da heteronormatividade. Tal conjunto costuma corresponder, de modo aproximado, a categorias êmicas como a sigla LGBT e outras aparentadas.

7 Da perspectiva aqui adotada, esse fenômeno é uma forma circunscrita, particular de politização da cultu$r a$, tema abordado de diferentes modos por autoras como Wright (1998) e Carneiro da Cunha (2009). Interessa sublinhar, nesses trabalhos, o modo como o conceito de "cultura" é operacionalizado na construção da(s) política(s) e o papel dos antropólogos nesse âmbito. Porém, o que aqui se quer destacar são as especificidades desse processo na construçáo de uma política "especificamente" cultural, ou seja, voltada à produção simbólica, ainda que, tal como se observa na construção das discursividades da Unesco e também do MinC, a dimensão "antropológica" da cultura se coloque como pertinente ao lado de outras duas: a econômica e a simbólica.

8 Um exemplo da resistência ao processo de reconhecimento da populaçáo LGBT como produtora de cultura vem da tramitaçáo na Câmara dos Deputados do Projeto de Lei no 122/2006 sobre a criminalização da homofobia. Na Comissão de Constituição e Justiça, o deputado José Divino (PMDB-RJ) argumentou que "homossexualismo [sic] não é uma cultura; os optantes náo vivem em culturas diferenciadas, eles convivem nas diversas classes sociais e culturais, não há como identificar um optante homossexual por sua cultura, raça ou cor" (Aguiāo, 2014, p. 122). Nesse sentido, é preciso situar a produção de uma política cultural LGBT no Brasil como parte dos esforços mais amplos que essa população instaura para "fixar sentidos positivos para a sua diferença" (Natividade, 2016, p. 21) num terreno sociopolítico bastante instável, onde as garantias de direitos esbarram na resistência de setores conservadores e fundamentalistas, setores que têm feito do Estado um locus ambivalente: ao mesmo tempo que ele significa a possibilidade da conquista de direitos, reconhecimento e aceitação, ali também se configuram as omissóes e as ameaças à população LGBT.
9 Dois segmentos específicos da população LGBT (os homens homossexuais e as transexuais) figuram como prioritários nas políticas voltadas à prevenção do HIV/Aids, no início caracterizados como "grupos de risco" e, atualmente, como "populaçóes-chave", junto com outros grupos sociais onde a incidência do vírus é maior do que na média da população em geral.

10 Segundo Lorena Muniagurria (2016, p. 12), em seu estudo sobre os agentes da sociedade civil nos espaços participativos da política cultural, "não apenas gestores, mas também fazedores de cultura concordavam que as contribuições da chamada sociedade civil foram, efetivamente, levadas em conta para a formulação das proposiçóes da política nacional. Os representantes da sociedade civil que participaram do processo se sentiam (co)autores do projeto e, como pude testemunhar posteriormente, se converteram nos principais agentes a divulgar e demandar sua implementação".

11 Todas as traduçôes deste artigo foram realizadas pelos autores.

12 A aproximação daquilo que hoje se denomina "movimento LGBT" aos poderes Executivo, Legislativo e Judiciário com o intuito de agendar a formulaçáo de políticas públicas vem, pelo menos, desde os anos 1980, mas ganhou impulso na década seguinte, com o surgimento e a difusão das Paradas do Orgulho pelo país (Facchini, 2009; Ramos; Carrara, 2006).

$13 \mathrm{O}$ GT e os primeiros editais lançados pelo MinC usam a sigla GLBT, vigente antes da I Conferência Nacional de Gays, Lésbicas, Bissexuais, Travestis e Transexuais, ocorrida em 2008, a partir da qual, em conformidade com o que já ocorria em outros países, passou-se a adotar a sigla LGBT, com o intuito de aumentar a visibilidade do segmento de lésbicas (Facchini, 2009).

14 Em outra chave, poderíamos caracterizar tal antagonismo como "recusa versus defesa da hétero-cis-normatividade".

15 Para uma análise das Paradas do Orgulho como eventos formadores da identidade coletiva da comunidade LGBT, bem como de constituição de sua formação política, ver Prado e Machado (2014). A respeito do percurso do sintagma "cultura de paz" no espaço público brasileiro, a circulação dessa fórmula discursiva e o modo como ela produz um efeito de consenso, ver Salgado e Boschi (2014).

16 Para um debate sobre as lutas em torno dos direitos humanos da comunidade LGBT, ver Pereira (2016).

17 Para uma análise do programa Brasil sem Homofobia, ver Rossi (2010). 
18 Embora o foco deste estudo tenha recaído sobre a noção de diversidade cultural, é certo que a abordagem da cultura de paz também exerce um papel importante na elucidaçáa desse problema. Conforme mostra Boschi (2018), o "apagamento do contradiscurso" está na própria gênese dos documentos da Unesco sobre a "cultura de paz", nos quais, por pressão da Uniâo Europeia, a enunciação da existência de uma "cultura da guerra e da violência" foi limada. A partir dos apontamentos de Duchêne (2004) sobre a "ideologia da objetividade", a autora chama a atençáo para o efeito de transparência e de consenso construído nos documentos produzidos por essas organizaçóes internacionais, nos quais prevalecem "a homogeneização da linguagem, o apagamento dos atores políticos e a eliminaçáo dos componentes emocionais do discurso" (Boschi, 2018, p. 858).

19 Para uma amostra da repercussáo midiática de tais episódios, ver Mendonça (2017), Valente (2017), Rocha (2017) e Garonce (2017).

\section{BIBLIOGRAFIA}

AGUIÃO, Sílvia. (2014), Fazer-se no "Estado": uma etnografia sobre o processo de constituição dos "LGBT" como sujeitos de direitos no Brasil contemporâneo. Tese de doutorado em Ciências Sociais, Campinas, Unicamp.

BARBALHO, Alexandre. (2005), "Cidadania, minorias e mídia. Ou algumas questóes que as minorias propóem ao liberalismo", in A. Barbalho e R. Paiva (orgs.). Comunicação e cultura das minorias, São Paulo, Paulus.

BARBALHO, Alexandre. (2007), "Políticas culturais no Brasil: identidade e diversidade sem diferença", in A. Barbalho e A. Rubim, Albino (orgs.), Politicas culturais no Brasil, Salvador, UFBA.

BOSCHI, Helena. (2018), "Cultura de paz”: gênese de uma fórmula entre discursos de guerra e violência. Trabalhos em Linguistica Aplicada, 57 (2): 848-876.

BOURDIEU, Pierre. (2014), Sobre o Estado. Curso no Collège de France (1989-1992). Lisboa, Ediçōes 70.

BRASIL. Ministério da Cultura. (s.d.), Apoio às Paradas do Orgulho GLBT. Brasília (DF): MinC.
Disponível em: <http://www.cultura.gov.br/ por-dentro-do-ministerio/-/asset_publisher/ dhdgdV8fiG9W/content/apoio-as-paradas-do-orgulho-gltb/10883>. Acesso em: 16 set. 2017.

BRASIL. Ministério da Cultura. Secretaria da Identidade e da Diversidade Cultural. (2005), Edital de Divulgação no 1, de 11 de março de 2005: Parada do Orgulho GLTB. Brasília, MinC.

BRASIL. Ministério da Cultura. Secretaria Executiva. (2006), Edital no 1: Concurso "Cultura GLTB”, de 19 de maio de 2006. Brasília, MinC.

BRASIL. Ministério da Cultura. Secretaria da Identidade e da Diversidade Cultural. (2007a), Edital de Divulgação no 2, de 18 de maio de 2007: Cultura GLTB. Brasília, MinC.

BRASIL. Ministério da Cultura. Gabinete do Ministro. (2007b), Portaria no 32, de 31 de julho de 2007. Brasília, MinC.

BRASIL. Ministério da Cultura. Secretaria da Identidade e da Diversidade Cultural. (2008a), Edital $n^{\circ}$ 9, de 15 de maio de 2008. Brasília, MinC.

BRASIL. Ministério da Cultura. Secretaria da Identidade e da Diversidade Cultural. (2008b), Edital no 10, de 15 de maio de 2008. Brasília, MinC.

BRASIL. Ministério da Cultura. Secretaria da Identidade e da Diversidade Cultural. (2009), Edital SID/MINC No 1, de 16 de março de 2009. Divulgação do Concurso Público Prêmio Cultural LGBT 2009. Brasília, MinC.

BRASIL. Presidência da República. Casa Civil. Subchefia para Assuntos Jurídicos. (2010), Decreto $n^{\circ} 7.388$, de 9 de dezembro de 2010. Brasília, Presidência da República.

BRASIL. Ministério da Cultura. (2012), Decreto $n^{\circ}$ 7.743, de 31 de maio de 2012. Brasília, MinC.

CAETANO, Marcio; NASCIMENTO, Claudio \& RODRIGUES, Alexsandro. (2018), "Do caos re-emerge a força: AIDS e mobilização LGBT”, in J. A. Green et al. (orgs.), História do movimento LGBT no Brasil, São Paulo, Alameda.

CARLOS, Euzeneia; PORTO DE OLIVEIRA, Osmany \& ROMÃO, Wagner de Mello (orgs.). (2014), Sociedade civil e politicas públicas: atores e instituiçôes no Brasil contemporâneo. Chapecó, Argos. 
CARNEIRO DA CUNHA, Manuela. (2009). Cultura com aspas e outros ensaios de antropologia. São Paulo, CosacNaify.

COELHO, Vera Schattan P. \& NOBRE, Marcos (orgs.). (2004), Participação e deliberação: teoria democrática e experiências institucionais no Brasil contemporâneo. São Paulo, Editora 34.

CÓRDULA, Américo. (2016), "Uma política para a diversidade cultural - 2003-2010", in A. Rubim (org.), Política cultural e gestão democrática no Brasil, São Paulo, Fundação Perseu Abramo.

CUÉLLAR, Javier Pérez de (org.). (1997), Nossa diversidade criadora. Relatório da Comissão Mundial de Cultura e Desenvolvimento. Campinas/Brasília, Papirus/Unesco.

DAGNINO, Evelina. (2004), Construção democrática, neoliberalismo e participação: os dilemas da confluência perversa. Política \& Sociedade, 5: 137-161.

FACCHINI, Regina. (2009), "Entre compassos e descompassos: um olhar para o "campo" e para a "arena" do movimento LGBT brasileiro". Bagoas, 4: 131-158.

FACCHINI, Regina. (2018), "Múltiplas identidades, diferentes enquadramentos e visibilidades: um olhar para os 40 anos do movimento LGBTI", in J. A. Green et al. (orgs.), História do movimento LGBT no Brasil, São Paulo, Alameda.

FEITOSA, Cleyton. (2018), "A participação social nos 40 anos de Movimento LGBT brasileiro", in J. A. Green et al. (orgs.), História do movimento LGBT no Brasil, São Paulo, Alameda.

FERREIRA, Juca (2005), "Um grande encontro no coração do Brasil: a mudança pela cultura”, in Seminário Nacional de Políticas Públicas para as Culturas Populares, Brasília, Ministério da Cultura.

GARONCE, Luiza. (2017), "Bancada evangélica na Câmara do DF pede revogação de política cultural LGBTI”, G1 DF, 2 out.

GILBERTO GIL. (2005), "Apresentação", in A. Lopes e L. Calabre (orgs.), Diversidade cultural brasileira, Rio de Janeiro, Fundação Casa de Rui Barbosa.

GREEN, James A. et al. (orgs.). (2018), História do movimento LGBT no Brasil. São Paulo, Alameda.
GURZA LAVALLE, Adrián. (2011), Após a participação. São Paulo, Cedec.

HOWARTH, D.; NORVAL, A. \& STAVRAKASIS, Y. (orgs.). (2009), Discourse, theory and political analysis. Manchester, Manchester University.

KAUARK, Giuliana. (2009), Oportuna diversidade: a participação do Ministério da Cultura do Brasil durante a negociação da Convenção sobre a Proteção e a Promoção da Diversidade das Expressóes Culturais. Dissertação de mestrado em Cultura e Sociedade, Salvador, UFBA.

LACLAU, Ernesto \& MOUFFE, Chantal. (2010), Hegemonia y estrategia socialista. Buenos Aires, Fondo de Cultura Económica.

MAMBERTI, Sérgio. (2005), "Políticas públicas: cultura e diversidade", in A. Lopes e L. Calabre, (orgs.), Diversidade cultural brasileira, Rio de Janeiro, Fundação Casa de Rui Barbosa.

MENDONÇA, Heloísa. (2017), "Queermuseu: O dia em que a intolerância pegou uma exposição para Cristo”. El País Brasil, 13 set.

MENDONÇA, Daniel de \& RODRIGUES, Léo Peixoto (orgs.). (2014), Pós-estruturalismo e teoria do discurso. Porto Alegre, PUC-RS.

MONTERO, Paula. (2012), Multiculturalismo, identidades discursivas e espaço público. Sociologia \& Antropologia, 2 (4): 81-101.

MUNIAGURRIA, Lorena Avellar de. (2016), As politicas da cultura: uma etnografia de trânsitos, encontros e militância na construção de uma politica nacional de cultura. Tese de doutorado, São Paulo, FFLCH-USP.

NATIVIDADE, Marcelo. (2016), Margens da politica: Estado, direitos sexuais e religióes. Rio de Janeiro, Garamond.

NICOLAU NETTO, Michel. (2017), "A diferença do discurso da diversidade". Contemporânea: revista de sociologia da UFSCar, 7: 39-61.

ONU. Declaration on a culture of peace. 1999a. Disponível em: <http://cpnn-world.org/resolutions/resA-53-243A.html>. Acesso em: 20 out. 2018.

ONU. Programme of action on a culture of peace. 1999b. Disponível em: <http://cpnn-world. org/resolutions/resA-53-243B.html>. Acesso em: 20 out. 2018. 
PEREIRA, Cleyton Feitosa. (2016), Direitos humanos de lésbicas, gays, bissexuais, travestis e transexuais em Pernambuco: o caso do Centro Estadual de Combate à Homofobia. Dissertação de mestrado, Recife, UFPE, Centro de Artes e Comunicação.

PIRES, Roberto Rocha C. (org.). (2011), A efetividade das instituiçôes participativas no Brasil: perspectivas, abordagens e estratégias de avaliação. Brasília, Ipea.

PRADO, Marco Aurélio \& MACHADO, Frederico. (2014), "Muito além do arco-íris. A constituição de identidades coletivas entre a sociedade civil e o Estado". Annual Review of Critical Psychology, 11: 151-170.

RAMOS, Silvia \& CARRARA, Sérgio. (2006), “A constituição da problemática da violência contra homossexuais: a articulação entre ativismo e academia na elaboração de políticas públicas". PHYSIS - Revista de Saúde Coletiva, 16 (2): $185-205$.

RIBEIRO, Gustavo Lins. (2014), Outras globalizaçôes. Rio de Janeiro, EdUERJ.

ROCHA, Pedro. (2017), "Justiça cancela apresentaçáa de peça que traz Jesus como mulher trans", Estadão, 16 set.

ROSSI, Alexandre José. (2010), Avanços e limites da politica de combate à homofobia: uma análise do processo de implementação das açōes para a educação do Programa Brasil sem Homofobia. Dissertação de mestrado em Educação, Porto Alegre, UFRGS.

SALGADO, Luciana Salazar \& BOSCHI, Helena Maria. (2014), "Gênese discursiva da fórmula 'cultura de paz". Acta Scientiarum. Language and Culture, 36 (2): 131-137.

SANTOS, Boaventura de Sousa (org.). (2003), Democratizar a democracia: os caminhos da democracia participativa. Rio de Janeiro, Civilização Brasileira.

SIMÔES, Júlio Assis \& FACHINNI, Regina. (2009), Na trilha do arco-iris: do movimento homossexual ao LGBT. São Paulo, Fundação Perseu Abramo.

SILVA, Tomaz Tadeu. (2000), Identidade e diferença. A perspectiva dos Estudos Culturais. Petrópolis, Vozes.
SODRÉ, Muniz. (2005), "Conceito de minoria". in A. Barbalho e R. Paiva (orgs.). Comunicação e cultura das minorias, São Paulo, Paulus.

TEIXEIRA, Ana Claudia Chaves. (2010), Para além do voto: uma narrativa sobre a democracia participativa no Brasil (1975-2010). Tese de doutorado em Ciências Sociais, Campinas, Unicamp.

TURINO, Célio. (2009), Ponto de Cultura: o Brasil de baixo para cima. Rio de Janeiro, Anita Garibaldi.

UNESCO. (2005), La convención de 2005 sobre la protección y la promoción de la diversidad de las expresiones culturales. Disponível em: <http:// en.Unesco.org/ creativity/sites/creativity/files/2811_16_passport_web_s.pdf>. Acesso em: 16 set. 2016.

VALENTE, Rubens. (2017), "Deputados pressionam, e polícia apreende quadro em exposição no MS". Folha de S.Paulo, 15 set.

WRIGHT, Susan. (1998), "The politization of culture”. Anthropology Today, 14 (1): 7-15.

YÚDICE, George. (2004), El recurso de la cultura. Barcelona, Gedisa. 


\section{ENTRE A DIVERSIDADE E O ANTAGONISMO: PRÁTICAS ARTICULATÓRIAS DA DISCURSIVIDADE LGBT NO MINISTÉRIO DA CULTURA}

\author{
Alexandre Almeida Barbalho e José de \\ Souza Muniz Jr.
}

Palavras-chave: Políticas culturais; Movimento LGBT; Discursividade.

Este trabalho tem por objeto um conjunto de programas, açóes e mecanismos institucionais do Ministério da Cultura (MinC) que passaram a contemplar a coletividade LGBT durante os governos de Lula e Dilma. O objetivo principal do estudo foi compreender a institucionalização das agendas culturais do movimento LGBT em âmbito federal. Analisamos documentos do MinC e depoimentos públicos de agentes desse universo recorrendo ao suporte da Teoria do Discurso (TD) de Laclau e Mouffe (2010), perspectiva segundo a qual a hegemonia opera num movimento de negociação entre discursos contraditórios, visando estabelecer relaçôes de ordem e aglutinação social. Nossa hipótese é que as ações do MinC, sobretudo os editais voltados à cultura LGBT, buscaram administrar os conflitos entre valores minoritários e hegemônicos na sociedade brasileira. Os antagonismos colocados pelas diferenças sexuais e culturais encampadas pelo movimento LGBT teriam sido neutralizados pelo discurso liberal da diversidade.

\section{BETWEEN DIVERSITY AND ANTAGONISM: ARTICULATORY PRACTICES OF LGBT DISCURSIVENESS IN THE BRAZILIAN MINISTRY OF CULTURE}

Alexandre Almeida Barbalho and José de Souza Muniz Jr.

Keywords: Cultural Politics; LGBT Movement; Discursivity

This work focuses on a set of programs, actions, and institutional mechanisms of the Brazilian Ministry of Culture (MinC) that began to contemplate the LGBT community during the governments of Lula and Dilma. The study intended to understand the institutionalization of the cultural agendas of the LGBT movement at the federal level. We analyze MinC documents and public testimonies of agents of this universe using the support of Laclau and Mouffe's Theory of Discourse (TD), a perspective according to which hegemony operates in a movement of negotiation between contradictory discourses, aiming to establish relations of order and social agglutination. We hypothesize that the MinC actions, especially the LGBT culture public announcements, sought to manage the conflicts between minority and hegemonic values in Brazilian society. The sexual and cultural differences embraced by the LGBT movement poses antagonisms that would have been neutralized by the liberal discourse of diversity.

\section{ENTRE LA DIVERSITÉ ET \\ L'ANTAGONISME: PRATIQUES \\ D'ARTICULATION DE LA \\ DISCURSIVITÉ LGBT AU MINISTĖRE DE LA CULTURE}

\author{
Alexandre Almeida Barbalho et José de \\ Souza Muniz Jr.
}

Mots-clés: Politiques culturelles; Mouvement LGBT; Discursivité.

Ce travail aborde un ensemble de programmes, d'actions et de mécanismes institutionnels du ministère de la Culture (MinC) qui ont passé à considérer la collectivité LGBT pendant les gouvernements de Lula et Dilma. L'objectif principal de l'étude a été de comprendre l'institutionnalisation des agendas culturels du mouvement LGBT au niveau fédéral. Nous avons analysé les documents du $\mathrm{MinC}$ et les déclarations publiques d'agents de cet univers à l'aide du soutien de la Théorie du Discours (TD) de Laclau et Mouffe (2010), une perspective selon laquelle l'hégémonie opère dans un mouvement de négociation entre des discours contradictoires, visant à établir des relations d'ordre et d'agglutination sociale. Notre hypothèse est que les actions du MinC, en particulier les appels d'offres destinés à la culture LGBT, ont cherché à gérer les conflits entre les valeurs minoritaires et hégémoniques dans la société brésilienne. Les antagonismes posés par les différences sexuelles et culturelles défendues par le mouvement LGBT auraient été neutralisés par le discours libéral de la diversité. 